\title{
Participatory Development and Preliminary Psychometric Properties of the User-Friendly Patient Information Material Checklist (UPIM-Check)
}

\author{
Sandra Salm ${ }^{1, * \mathbb{D}}$, Judith Mollenhauer ${ }^{1}$, Carolin Hornbach ${ }^{1}$, Natalia Cecon ${ }^{1}$, Antje Dresen ${ }^{1}$, Stefanie Houwaart ${ }^{2}$, \\ Anna Arning ${ }^{3}$, Andrea Göttel ${ }^{3}$, Kathrin Schwickerath ${ }^{3}$, Holger Pfaff ${ }^{1}{ }^{1}$, Nadine Scholten ${ }^{1}$ and Theresia Krieger ${ }^{1}$ \\ 1 Faculty of Human Sciences and Faculty of Medicine, Institute of Medical Sociology, Health Services Research, \\ and Rehabilitation Science (IMVR), University of Cologne, Eupener Str. 129, 50933 Cologne, Germany; \\ judith-m-@t-online.de (J.M.); carolin.hornbach@uk-koeln.de (C.H.); natalia.cecon@uk-koeln.de (N.C.); \\ antje.dresen@uk-koeln.de (A.D.); holger.pfaff@uk-koeln.de (H.P.); nadine.scholten@uk-koeln.de (N.S.); \\ theresia.krieger@uk-koeln.de (T.K.) \\ 2 House of the Cancer Patient Support Associations of Germany (HKSH-BV), Thomas-Mann-Str. 40, \\ 53111 Bonn, Germany; stefanie.houwaart@posteo.de \\ 3 Cancer Society North Rhine-Westphalia (KG-NRW), Volmerswerther Str. 20, 40221 Düsseldorf, Germany; \\ arning@krebsgesellschaft-nrw.de (A.A.); goettel@krebsgesellschaft-nrw.de (A.G.); \\ schwickerath@krebsgesellschaft-nrw.de (K.S.) \\ * Correspondence: sandra.salm@uk-koeln.de
}

Citation: Salm, S.; Mollenhauer, J.; Hornbach, C.; Cecon, N.; Dresen, A.; Houwaart, S.; Arning, A.; Göttel, A.; Schwickerath, K.; Pfaff, H.; et al. Participatory Development and Preliminary Psychometric Properties of the User-Friendly Patient Information Material Checklist (UPIM-Check). Int. J. Environ. Res. Public Health 2021, 18, 8773. https:// doi.org/10.3390/ijerph18168773

Academic Editors: Serena Barello and Guendalina Graffigna

Received: 7 July 2021

Accepted: 18 August 2021

Published: 19 August 2021

Publisher's Note: MDPI stays neutral with regard to jurisdictional claims in published maps and institutional affiliations.

Copyright: () 2021 by the authors. Licensee MDPI, Basel, Switzerland. This article is an open access article distributed under the terms and conditions of the Creative Commons Attribution (CC BY) license (https:// creativecommons.org/licenses/by/ $4.0 /)$.
Abstract: The aims of this study were (1) to design a user-friendly instrument to assess and optimize patient information material (PIM), (2) to develop an English version, and (3) to test its psychometric properties. The instrument was needed to optimize the top-down developed PIM of the psychooncological care programme isPO. First, a literature-based PIM checklist was developed by a team of patient representatives, cancer care experts and professional researchers. Next, the checklist's reliability and validity were analysed by having cancer survivors assess the initial and optimized version of the isPO-leaflet. The User-friendly Patient Information Material Checklist (UPIM-Check), developed participatorily, was found to be effective for evaluating PIM. It uses a traffic light scale, and suggestions for improvement can be given for each criterion. Its reliability appeared to be excellent ( $\alpha=0.927$ ). The optimized leaflet was rated significantly better than the initial one. The UPIM-Check is a reliable and valid instrument, which enables end-users (e.g., patients) to assess and optimize the quality of PIM according to scientific criteria and the needs of end-users. A bottom-up approach was essential for developing and validating the UPIM-Check. End-users constantly contributed with their specific knowledge. Thus, their position as co-researchers was significantly strengthened.

Keywords: quality assessment instrument; instrument development; psychometric properties; pilot study; patient information material; patient engagement; service provider engagement

\section{Introduction \\ 1.1. Patient Information Material (PIM)}

Patient information material (PIM) is written and audio-visual media developed to provide general information on a disease, its early detection, diagnosis and treatment or coping, without presupposing prior medical knowledge [1]. Such information is provided so patients can make health-related decisions [1] and are empowered to communicate with service providers [2]. Therefore, PIM is also of particular importance in intervention studies. Convincing PIM contributes to the acceptance and effective use of interventions [2]. Existing sets of criteria for PIM can guide the development of new PIM. They are similar in terms of structural, content-related and graphic requirements [1,3,4]. Furthermore, it is recommended to involve end-users in the development of PIM to ensure they contain easily readable, understandable and valid information for the end-users [1,3]. Thus, it may be useful to also determine criteria for PIM together with end-users. 
With this article, we would like to present how a user-friendly instrument to assess and optimize PIM was designed with end-user engagement. This is exemplified by the participatory optimization process of PIM in the German project isPO (integrated, crosssectoral Psycho-Oncology).

\subsection{The Psycho-Oncological Care Programme isPO and Its Project-Specific PIM}

The isPO project is developing, implementing, and evaluating a new, needs-driven psycho-oncological care programme $[5,6]$. The design process of this complex psychooncological intervention proved to follow a top-down approach [7]. Similarly, the projectspecific PIM for patient recruitment and study information also was developed with minor end-user participation. Both patients and service providers reported that the PIM for isPO (isPO-PIM) was too extensive, partly redundant and not linguistically appropriate for endusers (newly diagnosed cancer patients). This led to low programme acceptance by patients and especially made patient recruitment challenging. Therefore, the PIM was optimized by a team of cancer patient representatives from the House of the Cancer Patient Support Associations of Germany (HKSH-BV), experts from the Cancer Society North Rhine-Westphalia (KG-NRW) and health researchers of the University of Cologne. The entire optimization process [8] was guided by the participatory health research (PHR) approach according to Cornwall [9], with its six participation levels (Figure 1). Conducting PHR is a process of power-sharing, so participation levels can vary during the course of a project. The aim was to attain the 5th level of co-learning.

\begin{tabular}{|c|c|c|c|}
\hline & & $\begin{array}{l}\text { Relationship of } \\
\text { researchers to } \\
\text { end-users }\end{array}$ & Characteristics of participation \\
\hline \multirow{6}{*}{ 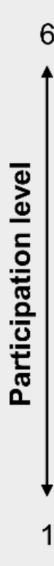 } & $\begin{array}{l}\text { Collective } \\
\text { action }\end{array}$ & $\begin{array}{l}\text { by } \\
\text { end-users }\end{array}$ & $\begin{array}{l}\text { end-users set their own agenda and mobilize to carry it out, in the absence of } \\
\text { outside researchers and facilitators }\end{array}$ \\
\hline & Co-learning & $\begin{array}{l}\text { with/by end- } \\
\text { users }\end{array}$ & $\begin{array}{l}\text { end-users and researchers share their knowledge, to create new } \\
\text { understanding, and work together to form action plans, with researcher } \\
\text { facilitation }\end{array}$ \\
\hline & Cooperation & $\begin{array}{l}\text { with } \\
\text { end-users }\end{array}$ & $\begin{array}{l}\text { end-users work together with researchers to determine priorities, responsibility } \\
\text { remains with researchers for directing the process }\end{array}$ \\
\hline & Consultation & $\begin{array}{l}\text { for/with end- } \\
\text { users }\end{array}$ & $\begin{array}{l}\text { end-users' opinions are asked, researchers analyse and decide on a course of } \\
\text { action }\end{array}$ \\
\hline & Compliance & $\begin{array}{l}\text { for } \\
\text { end-users }\end{array}$ & $\begin{array}{l}\text { tasks are assigned, with incentives; researchers decide agenda and direct the } \\
\text { process }\end{array}$ \\
\hline & Cooption & $\begin{array}{c}\text { on } \\
\text { end-users }\end{array}$ & token; representatives are chosen, but no real input or power \\
\hline
\end{tabular}

Figure 1. Participation levels, relationship of researchers to end-users, and characteristics of participation adapted from Cornwall (1996, p. 96).

The isPO-PIM optimization process gave rise to the need for a PIM assessment instrument following existing quality criteria. For the systematic evaluation of the isPO-PIM and the systematic collection of improvement suggestions at the same time, a PIM assessment and optimization instrument was needed. It was important to develop it with patient engagement, so that it corresponds to the PHR approach. Furthermore, existing PIM quality criteria had to be followed.

\subsection{PIM Assessment Instruments}

Besides the various sets of criteria for the quality of PIM, there are several validated instruments to assess PIM quality [2,10-13]. According to Clayton [12], PIM assessment instruments can be divided into three types-(1) attribute checklists, (2) readability tests, and (3) rating scales. Several literature reviews on PIM assessment instruments revealed 
the DISCERN as a commonly used rating instrument [2,4,12] (see below). Due to its specification to PIM on treatment choices and considering certain PIM quality criteria, new instruments have been developed in recent years $[2,12,13]$. Most of these rating instruments already have been applied in the context of cancer care [14-20].

In German-speaking countries, DISCERN [11] and the Patient Education Materials Assessment Tool (PEMAT) [13] have been used to assess cancer-related PIM [21,22].

Of these two instruments, only DISCERN was designed to be applied by professionals in health care, health research, and health policy as well as patients. Patients took part in the development and pilot testing of DISCERN, but not in the evaluation of its reliability. Both DISCERN and PEMAT are solely quantitative instruments assessing the quality of PIM with rating scales. Text fields for documenting improvement suggestions are not provided. Regarding the content, DISCERN focuses on the reliability and completeness of information, whereas PEMAT addresses structural and graphical requirements of PIM and assesses their actionability.

\subsection{Objective of This Study}

There was no PIM quality instrument available which could be intuitively applied, especially by PIM end-users. Moreover, existing instruments cannot be directly used for assessment as well as optimization of PIM, e.g., with open text fields for improvement suggestions. More particularly, the usually applied German-speaking PIM instruments do not cover all PIM quality areas. Hence, within the process of optimizing the isPO-PIM, a criteria-based User-friendly $\underline{\text { Patient }} \underline{\text { Information }}$ Material Checklist (UPIM-Check) was developed with perpetual engagement of end-users. It was designed to enable quantitative assessment as well as the optimization of PIM.

In this paper, we report on: (1) the participatory development of the UPIM-Check, (2) the translation process into English, and (3) the psychometric pilot study of the German version.

\section{Materials and Methods}

\subsection{Ethical Approval}

The study was performed according to the Declaration of Helsinki. The ethics committee of the Medical Faculty of the University of Cologne has approved the isPO project and its study design (No. 18-092; date of approval: 15 October 2018). The relevant national and European data protection regulations were considered for data collection. The isPO project study is registered in the German Clinical Trials Register (No. DRKS00015326).

\subsection{Development of the UPIM-Check (German Version)}

The development of the UPIM-Check took place in a multi-step process, which is shown in Figure 2. It was part of the preparation phase within the isPO-PIM optimization process [8], so the team composition of patient representatives, cancer care experts and researchers was identical. 


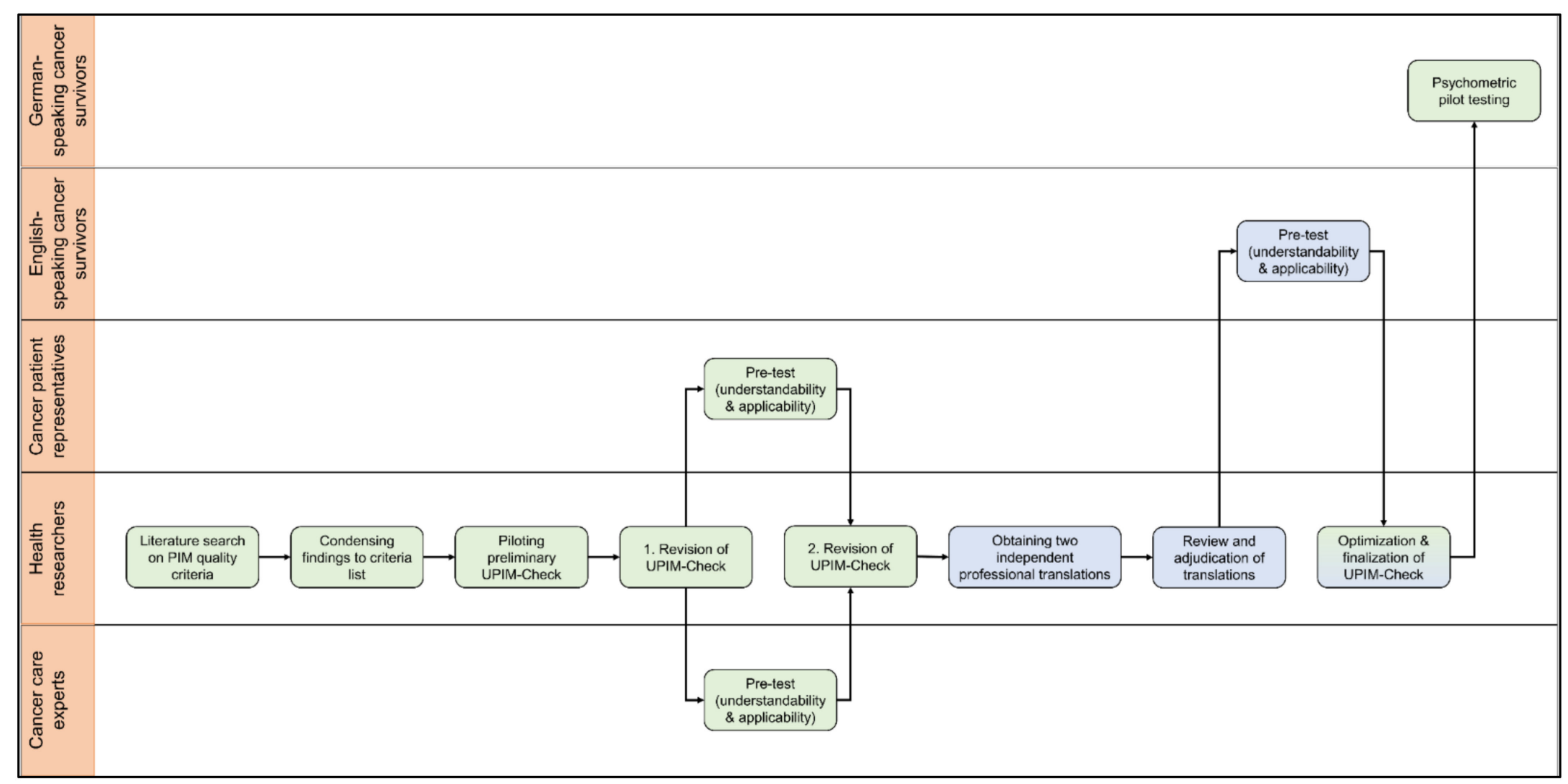

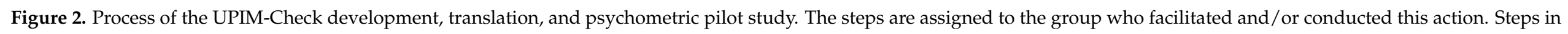
green represent the UPIM-Check German version, steps in blue represent the UPIM-Check English version. 
The design of the new PIM quality instrument was based on the literature on quality criteria and creation manuals for written PIM [1-3]. In addition to the written isPOPIM (leaflets and information folders) there is also an isPO website for patients who are interested in taking advantage of the isPO care programme. So, literature on web-based PIM was also included [4]. The quality criteria that were found were first condensed to a set of 27 criteria by one person from the group of researchers and then grouped into four areas based on the quality indicators of Herm and Linden [3]. This preliminary version of the UPIM-Check was structured into the two sections Correctness and validity of content (Does the information appear to be correct and valid?) and Readability with the three sub-sections Readability of content (Is the content easy to read and the used language appropriate for the end-users?), Structural readability (Is the word and sentence complexity appropriate for the end-users?), and Graphical readability (Is the graphical design appropriate for the end-users?). For an intuitive assessment of the criteria, a three-point traffic light scale was chosen. The new instrument had to be designed to both assess and optimize PIM, so evaluation and improvement suggestions come from one source to make the instrument efficient. Therefore, an open text field for suggestions for improvement was assigned to each criterion. Three further researchers from the isPO-PIM team piloted the preliminary version of the UPIM-Check and added four items based on the literature mentioned above.

To pre-test the UPIM-Check, it was presented to the other isPO-PIM team members ( $n=5$; two patient representatives and three cancer care experts) to test it on the isPO-PIM. They were asked to critically review it in terms of comprehensibility and applicability. Improvement ideas were inserted on the UPIM-Check form and the UPIM-Check was adapted. In particular, patient representatives suggested linguistic changes to improve clarity and to use language that would empower patients (i.e., motivating them and guiding their actions).

\subsection{English Translation of the UPIM-Check}

To make the UPIM-Check internationally available, an English-language version was generated according to the TRAPD approach (Translation, Review, Adjudication, Pretest, and Documentation) $[23,24]$. The basis was the pre-tested and adapted UPIM-Check German version.

Two professional translators independently translated the UPIM-Check into English (T). A team of four researchers who were active in (psycho-)oncological health services research was formed. Three of them were involved in the development and/or piloting of the preliminary UPIM-Check German version. The fourth person was a native English speaker with eight years of German language experience. Together, they reviewed the two English translations in relation to the German version $(\mathrm{R})$. As the two translations were very similar, linguistic subtleties had to be discussed (e.g., "appropriate" vs. "adequate"). To consent the final English version (A), linguistic consistency within the instrument and an easy language were guiding this step.

The pre-test $(\mathrm{P})$ of the English version had to take place in written form instead of face-to-face interviews, so a special UPIM-Check pre-test form was created. It had an open text field below each criterion so respondents could enter comments on the comprehensibility and relevance of the criterion. In addition, a final text field was available for general comments on the UPIM-Check. To make the UPIM-Check applicable and the comments comparable, the same PIM was made available to all English version pretest participants. Freely available leaflets on psycho-oncological care in English-speaking countries were researched using an internet search engine. The isPO-PIM team then selected a leaflet published by the national health system of an English-speaking country based on seriousness and independence. The pre-test documents included an invitation letter explaining the aim of the UPIM-Check and how the pre-test would be conducted.

Several methods were used to recruit participants for the pre-test of the English version: The contacts of the HKSH-BV to English-speaking sister organizations were used, and further cancer self-help associations in the UK and USA were identified. In each case, 
the chairpersons were contacted by email and asked to distribute the pre-test documents to their members. Nine organizations were contacted in up to two contact attempts.

One person each from four organizations provided written feedback on the UPIMCheck. That feedback was incorporated into the final English version of the UPIM-Check. In the pre-test of the English version, it was suggested for some items to formulate them as questions. To be consistent throughout the instrument, the criteria were still formulated as key terms, but questions were added to every item, guiding its assessment (e.g., "Neutral language -Is the PIM presented in an open-minded, not manipulation way?"; "IllustrationsAre the pictures and graphics used concise and understandable?"). Consequently, these questions were also added to the German version to align the both language versions.

\subsection{Pilot Study on the Psychometric Properties of the UPIM-Check German Version}

2.4.1. Pilot Study Design and Participant Recruitment

Since the UPIM-Check was originally developed in German, this version was tested for its psychometric properties first. It was presented to cancer survivors who had no connection to the isPO project or the development of the UPIM-Check. Two versions of the isPO leaflets were assessed-the initial one and the optimized one. To avoid bias because of preconceptions, the study invitation stated only that two leaflets on psychooncological care were presented, but not that they were based on an optimization process. Two study groups were defined: (1) participants who evaluated the initial leaflet first and the optimized one second, and (2) participants who evaluated the optimized leaflet first and the initial one second.

Participants for the pilot study were recruited from: (1) the ten associations in the patient organization HKSH-BV, (2) the eight associations in the self-help section of the cancer care expert organization KG-NRW, and (3) Facebook groups organized by and for cancer patients. Up to two contact attempts for each organization were made.

To guarantee their anonymity, interested persons were asked to provide their postal address to the isPO-Trust Centre, which was separate from the research staff in terms of personnel and space.

The recruits were randomly assigned to one of two study groups and given numbers to be used as pseudonyms. Two copies of the UPIM-Check were given to each person, one for each version of the isPO-leaflet.

At the end of the pilot study, all participants received a written report on the results and the UPIM-Check German version for free use.

\subsubsection{Materials}

The following materials were sent to the pilot study participants by the isPO-Trust Centre to carry out the two assessments: an application guide and two envelopes, each containing a copy of the UPIM-Check and one of the two leaflets. The application guide was a one-page document explaining step-by-step how to conduct the UPIM-Check pilot testing. In this way, the pilot study participants were instructed to open the envelopes and apply the UPIM-Checks in the specified order. The envelopes were numbered according to the study group. For participants in group 1, envelope no. 1 contained the original leaflet and envelope no. 2 contained the optimized leaflet; for study group 2, the numbering was reversed.

After they completed the UPIM-Checks, the participants were asked to return them to the isPO-Trust Centre in an enclosed return envelope.

The UPIM-Check form used for the psychometric pilot study contained some additional elements for study purposes. These included demographics such as age, gender and tumour entity. The time efficiency of the UPIM-Check was also measured. Participants used text fields to enter the times when the UPIM-Check was started and completed. This information was used to calculate the completion time in minutes.

The traffic light scale of the UPIM-Check was operationalised as a three-point Likert scale with the following options: $1=$ very good; $2=$ sufficient; $3=$ unsatisfactory. The UPIM- 
Check total score and the four criteria areas as subscale scores were calculated as the sum of the corresponding items, with a lower score representing a better rating.

\subsubsection{Statistical Analysis}

To explore the psychometric properties of the German UPIM-Check, item acceptance, discriminatory power, internal consistency, and construct validity were tested. All analyses were performed to assess both the initial and the optimized isPO-leaflet.

Item acceptance was assessed by the completion rate; the higher the rate, the greater the acceptance of the item [25]. For each item, the percentage of pilot study participants who answered it was calculated.

Item discrimination is the extent to which the differentiation of subjects within an item corresponds to that within the total score [26]. Thus, the corrected item-scale correlations were computed. This was the correlation between an item and the score of the remaining items [27]. Item-total correlations $>0.20$ were considered acceptable [28,29].

Internal consistency is a measure of the inter-relation of items [30]. Hence, Cronbach's $\alpha$ [31] was calculated, with values between 0.0 and 1.0. Values $>0.70$ were considered acceptable, values $>0.80$ good and values $>0.90$ excellent [30].

Construct validity refers to whether an instrument really measures the construct that it claims to measure [30]. As construct validity cannot be directly measured, its assessment comprises the formulation of hypotheses concerning the relationships of constructs [29,30]. To assess the evidence for the construct validity of the UPIM-Check, the following hypothesis was formulated:

Hypothesis 1: The UPIM-Check total score correlates highly positively with the four UPIM-Check subscale scores.

Furthermore, we explored the ability of the UPIM-Check to discriminate between an initial and an optimized PIM, and the time-efficiency of the instrument:

Hypothesis 2: The UPIM-Check total score on the optimized isPO-leaflet is significantly lower than the total score on the initial leaflet.

Hypothesis 3: The UPIM-Check total score correlates positively with the completion time since a lower rating requires more improvement suggestions.

To test the first and third hypotheses, Spearman's correlation was calculated one-sided and interpreted according to Taylor [32]: 0.0 to $0.35=$ weak correlation; 0.36 to $0.67=$ moderate correlation; 0.68 to $1.0=$ high correlation. For the second hypothesis, the Wilcoxon test was performed as a non-parametric test for dependent samples.

To test the hypotheses, a significance level of $\alpha=0.05$ was assumed and adjusted to $\alpha=0.0125$ for hypothesis 1 and to $\alpha=0.025$ for hypothesis 3 according to the Bonferroni correction.

Data input, preparation and analysis were performed using IBM SPSS Statistics 27. The data were input manually by the first author, and they were checked by another author, using a dual control principle. For missing values, pairwise deletion was applied.

\section{Results}

\subsection{The UPIM-Check-Structure and Application}

The final UPIM-Check is an instrument for both assessing and optimizing the quality of PIM. It has 31 items, which are divided into four quality areas: Q1: Correctness and validity of content (9 items), Q2: Readability of content (8 items), Q3: Structural readability (4 items), and Q4: Graphical readability (10 items).

To map Q1, items were developed to assess the information basis of the PIM. The relevance of such information is decisive for the end-users, as well as whether the PIM gives concrete recommendations for action. Q2 focuses on whether the PIM is designed in such a way that the end-users are specifically addressed and the linguistic design corresponds 
to the end-users. Delimited from this superordinate level, Structural Readability (Q3) focuses on features at the word and sentence levels. $Q 4$ takes up the graphic design of the PIM. This refers to the information provided by illustrations and to the visual design and structuring of the text.

The items of the UPIM-Check represent concrete criteria and contain questions to help users assessing the criterion. The evaluation itself is quantitative, using a traffic light scale with the levels very good (green), sufficient (yellow) and unsatisfactory (red). For its function as an optimization tool, the UPIM-Check provides an open text field for suggestions for improvement for each criterion. The field can be used if a criterion is rated yellow or red. Figure 3 shows an excerpt from the English version of the UPIM-Check.

\begin{tabular}{|l|l|l|l|l|l|}
\hline Quality criteria & \multicolumn{1}{c|}{$\begin{array}{c}\text { very } \\
\text { good }\end{array}$} & $\begin{array}{c}\text { suffi- } \\
\text { cient }\end{array}$ & $\begin{array}{c}\text { unsatis- } \\
\text { factory }\end{array}$ & Suggestions for improvement \\
\hline Q1: Correctness \& validity of content - Does the content seem to be correct? Does the information appear to be valid? \\
\hline Q1.1 & $\begin{array}{l}\text { Up-to-date \& technically correct } \\
\text { (references, expertise of the authors, date) } \\
\text { Does the information appear to be up-to-date? } \\
\text { Is the information correctly cited? }\end{array}$ & $\square$ & $\square$ & $\square$ & \\
\hline Q1.2 & $\begin{array}{l}\text { Transparency } \\
\text { (author of the PIM; contact person, contact \& } \\
\text { logo) } \\
\text { How clear is the information? }\end{array}$ & $\square$ & $\square$ & $\square$ & \\
\hline Q1.3 & $\begin{array}{l}\text { Information is relevant for the target group } \\
\text { (social evidence) } \\
\text { Is the information relevant for the target group? }\end{array}$ & $\square$ & $\square$ & $\square$ & \\
\hline Q1.4 & $\begin{array}{l}\text { Contextual integration into patient's situation } \\
\text { (experience, emotions, burden) } \\
\text { How does the information fit the patient's } \\
\text { situation? }\end{array}$ & $\square$ & $\square$ & $\square$ & \\
\hline
\end{tabular}

Figure 3. Excerpt from the User-Friendly Patient Information Material Checklist (UPIM-Check) English version. Available at https://www.imvr.de/wp-content/uploads/UPIM-Check_English.pdf, accessed on 18 August 2021.

On the first page of the UPIM-Check, information about the assessment process itself can be given: (1) name of the PIM, (2) role of the rater (e.g., patient/patient representative, researcher/project staff, care provider), and (3) information on where and how the endusers come into contact with the PIM. Section 2 is intended to support the cooperation of persons with different perspectives in the development, assessment and optimization of PIM, and Section 3 aims to classify the PIM within a communication strategy. That is, if several PIMs with different objectives and different end-users were to be used in a project. The UPIM-Check is freely available at https: / / www.imvr.de/wp-content/uploads/UPIMCheck_English.pdf, accessed on 18 August 2021.

\subsection{Preliminary Psychometric Properties of the UPIM-Check German Version}

A total of 18 cancer survivors took part in the psychometric pilot study, although one person completed the UPIM-Check only on the optimized leaflet. Pilot study participant characteristics are presented in Table 1.

Table 1. Participant characteristics of the UPIM-Check German version psychometric pilot study.

\begin{tabular}{ccc}
\hline Characteristic & $M(S D)$ & Range \\
\hline Age (years) & $65.28(9.49)$ & $42-79$ \\
\hline Gender & $f$ & $\%$ \\
female & 5 & \\
male & 13 & 72.8 \\
\hline Tumour entity & 11 & \\
Bladder & 6 & 61.1 \\
Head and Neck & 1 & 33.3 \\
Other & &
\end{tabular}


Item acceptance ranged from $88.2 \%$ to $100 \%$ for the initial leaflet and from $83.3 \%$ to $100 \%$ for the optimized leaflet (Table 2). The item with the lowest acceptance was Q2.8 Use of empowering words.

Table 2. Item and score characteristics of the UPIM-Check German version according to the rating of the initial and optimized isPO-leaflet.

\begin{tabular}{|c|c|c|c|c|c|c|c|c|c|c|}
\hline \multirow[b]{2}{*}{ Item/Score } & \multicolumn{5}{|c|}{ Initial Leaflet } & \multicolumn{5}{|c|}{ Optimized Leaflet } \\
\hline & $M$ & $S D$ & $\begin{array}{l}\text { Fill-In } \\
\text { Rate (\%) }\end{array}$ & $\begin{array}{l}\text { Corrected } \\
\text { Item-Total } \\
\text { Correlation }\end{array}$ & $\begin{array}{c}\text { Cronbach's } \\
\alpha\end{array}$ & $M$ & $S D$ & $\begin{array}{c}\text { Fill-In } \\
\text { Rate (\%) }\end{array}$ & $\begin{array}{l}\text { Corrected } \\
\text { Item-Total } \\
\text { Correlation }\end{array}$ & $\begin{array}{c}\text { Cronbach's } \\
\alpha\end{array}$ \\
\hline UPIM-Check total & 44.08 & 10.86 & & & 0.927 & 38.36 & 4.48 & & & 0.655 \\
\hline $\begin{array}{l}\text { Q1: Correctness and } \\
\text { validity of content }\end{array}$ & 12.63 & 3.65 & & & 0.806 & 11.76 & 2.33 & & & 0.594 \\
\hline $\begin{array}{l}\text { Q1.1 Up-to-date and } \\
\text { technically correct }\end{array}$ & 1.24 & 0.56 & 100 & 0.052 & & 1.39 & 0.70 & 100 & 0.047 & \\
\hline Q1.2 Transparency & 1.06 & 0.24 & 100 & 0.263 & & 1.47 & 0.72 & 94.4 & 0.381 & \\
\hline $\begin{array}{l}\text { Q1.3 Information is } \\
\text { relevant for the target } \\
\text { group }\end{array}$ & 1.13 & 0.50 & 94.1 & 0.727 & & 1.11 & 0.32 & 100 & 0.376 & \\
\hline $\begin{array}{l}\text { Q1.4 Contextual } \\
\text { integration into } \\
\text { patient's situation }\end{array}$ & 1.56 & 0.81 & 94.1 & 0.791 & & 1.22 & 0.43 & 100 & 0.626 & \\
\hline Q1.5 Focus & 1.35 & 0.61 & 100 & 0.897 & & 1.06 & 0.24 & 94.4 & 0.309 & \\
\hline $\begin{array}{l}\text { Q1.6 Adequate } \\
\text { presentation }\end{array}$ & 1.65 & 0.79 & 100 & 0.665 & & 1.33 & 0.59 & 100 & 0.626 & \\
\hline $\begin{array}{l}\text { Q1.7 Motivation and } \\
\text { increase of } \\
\text { self-efficacy }\end{array}$ & 1.41 & 0.62 & 100 & 0.736 & & 1.22 & 0.43 & 100 & 0.472 & \\
\hline $\begin{array}{l}\text { Q1.8 Recommendation } \\
\text { for action } \\
\text { Q1.9 Further }\end{array}$ & 1.53 & 0.62 & 100 & 0.736 & & 1.24 & 0.56 & 94.4 & -0.174 & \\
\hline $\begin{array}{l}\text { literature/points of } \\
\text { contact }\end{array}$ & 1.59 & 0.80 & 100 & -0.058 & & 2.06 & 0.80 & 100 & 0.145 & \\
\hline $\begin{array}{l}\text { Q2: Readability of } \\
\text { content }\end{array}$ & 11.42 & 4.21 & & & 0.929 & 9.47 & 1.68 & & & 0.625 \\
\hline $\begin{array}{l}\text { Q2.1 Aim of the PIM } \\
\text { and target group is } \\
\text { identifiable }\end{array}$ & 1.31 & 0.60 & 94.1 & 0.897 & & 1.06 & 0.24 & 94.4 & 0.309 & \\
\hline Q2.2 Clarity of content & 1.44 & 0.63 & 94.1 & 0.943 & & 1.29 & 0.59 & 94.4 & 0.359 & \\
\hline $\begin{array}{l}\text { Q2.3 Simple, clear } \\
\text { language }\end{array}$ & 1.29 & 0.59 & 100 & 0.897 & & 1.11 & 0.32 & 100 & 0.309 & \\
\hline Q2.4 Neutral language & 1.24 & 0.56 & 100 & 0.727 & & 1.06 & 0.24 & 100 & a & \\
\hline $\begin{array}{l}\text { group-specific } \\
\text { language }\end{array}$ & 1.53 & 0.74 & 88.2 & 0.603 & & 1.39 & 0.70 & 100 & 0.626 & \\
\hline Q2.6 Use of numbers & 1.13 & 0.35 & 88.2 & 0.263 & & 1.18 & 0.39 & 94.4 & 0.023 & \\
\hline $\begin{array}{l}\text { Q2.7 Language that } \\
\text { can be understood } \\
\text { without prior medical } \\
\text { knowledge }\end{array}$ & 1.75 & 0.78 & 94.1 & 0.795 & & 1.44 & 0.62 & 100 & 0.070 & \\
\hline $\begin{array}{l}\text { Q2.8 Use of } \\
\text { empowering words }\end{array}$ & 1.60 & 0.74 & 88.2 & 0.895 & & 1.40 & 0.63 & 83.3 & .292 & \\
\hline $\begin{array}{l}\text { Q3: Structural } \\
\text { readability }\end{array}$ & 5.19 & 1.76 & & & 0.822 & 4.59 & 1.12 & & & 0.803 \\
\hline Q3.1 Sentence length & 1.18 & 0.39 & 100 & 0.068 & & 1.17 & 0.51 & 100 & a & \\
\hline $\begin{array}{l}\text { Q3.2 Sentence } \\
\text { difficulty/complexity }\end{array}$ & 1.24 & 0.44 & 100 & 0.264 & & 1.12 & 0.33 & 94.4 & -0.146 & \\
\hline Q3.3 Word length & 1.29 & 0.59 & 100 & 0.374 & & 1.17 & 0.38 & 100 & -0.146 & \\
\hline Q3.4 Word difficulty & 1.56 & 0.73 & 94.1 & 0.248 & & 1.39 & 0.61 & 100 & 0.177 & \\
\hline
\end{tabular}


Table 2. Cont.

\begin{tabular}{|c|c|c|c|c|c|c|c|c|c|c|}
\hline \multirow[b]{2}{*}{ Item/Score } & \multicolumn{5}{|c|}{ Initial Leaflet } & \multicolumn{5}{|c|}{ Optimized Leaflet } \\
\hline & $M$ & $S D$ & $\begin{array}{c}\text { Fill-In } \\
\text { Rate (\%) }\end{array}$ & $\begin{array}{l}\text { Corrected } \\
\text { Item-Total } \\
\text { Correlation }\end{array}$ & $\begin{array}{c}\text { Cronbach's } \\
\alpha\end{array}$ & $M$ & $S D$ & $\begin{array}{c}\text { Fill-In } \\
\text { Rate (\%) }\end{array}$ & $\begin{array}{l}\text { Corrected } \\
\text { Item-Total } \\
\text { Correlation }\end{array}$ & $\begin{array}{c}\text { Cronbach's } \\
\alpha\end{array}$ \\
\hline $\begin{array}{l}\text { Q4: Graphical } \\
\text { readability }\end{array}$ & 13.67 & 3.54 & & & 0.803 & 12.33 & 2.50 & & & 0.607 \\
\hline $\begin{array}{l}\text { Q4.1 Layout/overall } \\
\text { visual appearance }\end{array}$ & 1.59 & 0.71 & 100 & 0.226 & & 1.33 & 0.49 & 100 & 0.412 & \\
\hline Q4.2 Eye-catching & 2.00 & 0.73 & 94.1 & 0.452 & & 1.59 & 0.80 & 94.4 & 0.208 & \\
\hline $\begin{array}{l}\text { Q4.3 Appropriate } \\
\text { overall text length }\end{array}$ & 1.35 & 0.70 & 100 & 0.576 & & 1.28 & 0.58 & 100 & 0.316 & \\
\hline $\begin{array}{l}\text { Q4.4 Structure and } \\
\text { context }\end{array}$ & 1.12 & 0.33 & 100 & 0.263 & & 1.33 & 0.69 & 100 & 0.330 & \\
\hline $\begin{array}{l}\text { Q4.5 Illustrations } \\
\text { Q4.6 Coloured }\end{array}$ & 1.76 & 0.83 & 100 & 0.590 & & 1.69 & 0.95 & 88.9 & 0.425 & \\
\hline $\begin{array}{l}\text { headings and } \\
\text { highlighting of key } \\
\text { points }\end{array}$ & 1.24 & 0.44 & 100 & -0.175 & & 1.22 & 0.43 & 100 & -0.160 & \\
\hline Q4.7 Font size & 1.19 & 0.54 & 94.1 & 0.724 & & 1.00 & 0.00 & 94.4 & a & \\
\hline Q4.8 Font colour & 1.18 & 0.39 & 100 & -0.061 & & 1.06 & 0.24 & 94.4 & -0.271 & \\
\hline Q4.9 Font type & 1.18 & 0.39 & 100 & 0.620 & & 1.11 & 0.32 & 100 & -0.395 & \\
\hline $\begin{array}{l}\text { Q4.10 Corporate } \\
\text { design }\end{array}$ & 1.25 & 0.58 & 94.1 & 0.825 & & 1.33 & 0.59 & 100 & 0.286 & \\
\hline
\end{tabular}

Note. ${ }^{a}$ Item was removed from reliability analysis because it has a variance of zero.

The corrected item-total correlations ranged between -0.175 and 0.943 for the initial leaflet and between -0.395 and 0.626 for the optimized leaflet. A total of 26 items for the initial leaflet and 17 items for the optimized leaflet had a corrected item-total correlation of $>0.20$ (Table 2). Three items were removed from the reliability analysis of the optimized leaflet because their variance was zero. These were Q2.4 Neutral language, Q3.1 Sentence length and Q4.7 Font size. Cronbach's $\alpha$ was 0.927 for the initial leaflet and 0.655 for the optimized leaflet.

The mean UPIM-Check total score was $M=44.08(S D=10.86)$ for the initial leaflet and $M=38.36(S D=4.48)$ for the optimized leaflet. Corresponding information on the subscale scores can be found in Table 2. On average, participants needed $25.18 \mathrm{~min}(S D=28.09 \mathrm{~min})$ to complete the UPIM-Check for the initial leaflet and $21.18 \mathrm{~min}(S D=20.27 \mathrm{~min})$ to complete the UPIM-Check for the optimized leaflet.

The scores on the Wilcoxon test were significantly lower for the total score for the optimized leaflet than for the initial leaflet $(Z=-2.606 ; p=0.009)$. This showed that the UPIM-Check could discriminate PIM versions of different quality.

The Spearman's correlations of the UPIM-Check total score with the subscale scores for the initial leaflet ranged from $r=0.594$ to $r=0.923$. The correlations with the subscales $Q 1$ : Content correctness and validity and $Q 2$ : Content readability were significant $(p<0.001)$ (Table 3). Regarding the optimized leaflet, the correlations ranged from $r=0.301$ to $r=0.753$, with significant correlations with subscale Q1 $(p=0.001)$ and subscale Q2 $(p=0.006)$. The correlation with subscale $Q 4$ : Graphic Readability was also significant $(p=0.004)$.

The respective correlations of the UPIM-Check total score with the duration of completion for the two versions of the leaflet showed a significant positive correlation for the initial leaflet $(r=0.685 ; p=0.010)$ and the optimized leaflet $(r=0.606 ; p=0.014)$.

The results show that the UPIM-Check is a precise instrument and efficient to use. 
Table 3. Spearman's correlations of the UPIM-Check total score with subscale scores according to the initial and optimized isPO-leaflet.

\begin{tabular}{lcccc}
\hline \multirow{2}{*}{ Subscale Score } & \multicolumn{2}{c}{$\begin{array}{c}\text { UPIM-Check Total Score } \\
\text { (Initial Leaflet) }\end{array}$} & \multicolumn{2}{c}{$\begin{array}{c}\text { UPIM-Check Total Score } \\
\text { (Optimized Leaflet) }\end{array}$} \\
\cline { 2 - 5 } & $\boldsymbol{r}$ & $\boldsymbol{p}$ & $\boldsymbol{r}$ & $\boldsymbol{p}$ \\
\hline Q1: Correctness and validity of content & $0.919^{*}$ & $<0.001$ & $0.753 *$ & 0.001 \\
Q2: Readability of content & $0.923^{*}$ & $<0.001$ & $0.645^{*}$ & 0.006 \\
Q3: Structural readability & 0.637 & 0.013 & 0.301 & 0.148 \\
Q4: Graphical readability & 0.594 & 0.021 & $0.679 *$ & 0.004 \\
\hline
\end{tabular}

Note. ${ }^{*}$ Significant correlation according to $\alpha=0.0125$.

\section{Discussion}

This work shows how an end-user-friendly quality instrument for written PIM (UPIM-Check) was developed with ongoing end-user engagement (Figure 4). Besides, it serves as a structured assessment and optimization tool for PIM. The availability of the instrument in German and English widens its usability. Preliminary data on the psychometric properties of the German version were presented first. Validation of the English version is still to be conducted, for which we are looking for interested cooperation partners.

The UPIM-Check was developed to be (1) intuitively usable by all PIM end-users, (2) applicable for both assessment and optimization of PIM and (3) based on scientific criteria for the quality of PIM.

All isPO-PIM team members found their team composition (patient representatives, cancer care experts, and researchers) to be fruitful and enlightening. In particular, the end-users were strengthened in their roles as co-researchers, so that collaboration took place on an equal footing. Moreover, exploring three different perspectives provided a valuable impetus to make the UPIM-Check scientifically and linguistically appropriate, and applicable for end-users. Patient representatives offered the following observations: "The checklist covers a lot of aspects, so you get a "close up" of the material'. There is a 'reasonable assurance that patients would be able to comprehend the checklist'.

Nevertheless, the PHR approach also involves some bottlenecks. Krieger et al. [33] found that communication between different groups was very resource-intensive. Knowing this beforehand, we carefully planned and implemented the communication channels between the isPO-PIM team members. It was essential to provide an equal level of information to all team members, as 'knowledge is power', and the PHR approach demands power balance [34]. Also, recruiting people from the end-user group during the COVID-19 pandemic was challenging, e.g., in studies with older people and in oncological trials $[35,36]$.

In the psychometric pilot study, an initial and an optimized leaflet for the psychooncological care programme isPO were assessed with the UPIM-Check by cancer survivors of various patient organizations representing different tumour entities. Thus, diversity of perspectives was achieved.

While the internal consistency of the initial leaflet was excellent, it was just below an acceptable value for the optimized version. However, comparability was limited because only 28 of the 31 items were included in the analysis of the optimized leaflet because some variances were zero. This could lead to an underestimation of reliability [37]. The low dispersion in the evaluation of the optimized leaflet could also indicate a high rater agreement, so PIM of very high quality could be achieved especially for three criteria (Q2.4 Neutral language, Q3.1 Sentence length, Q4.7 Font size). 


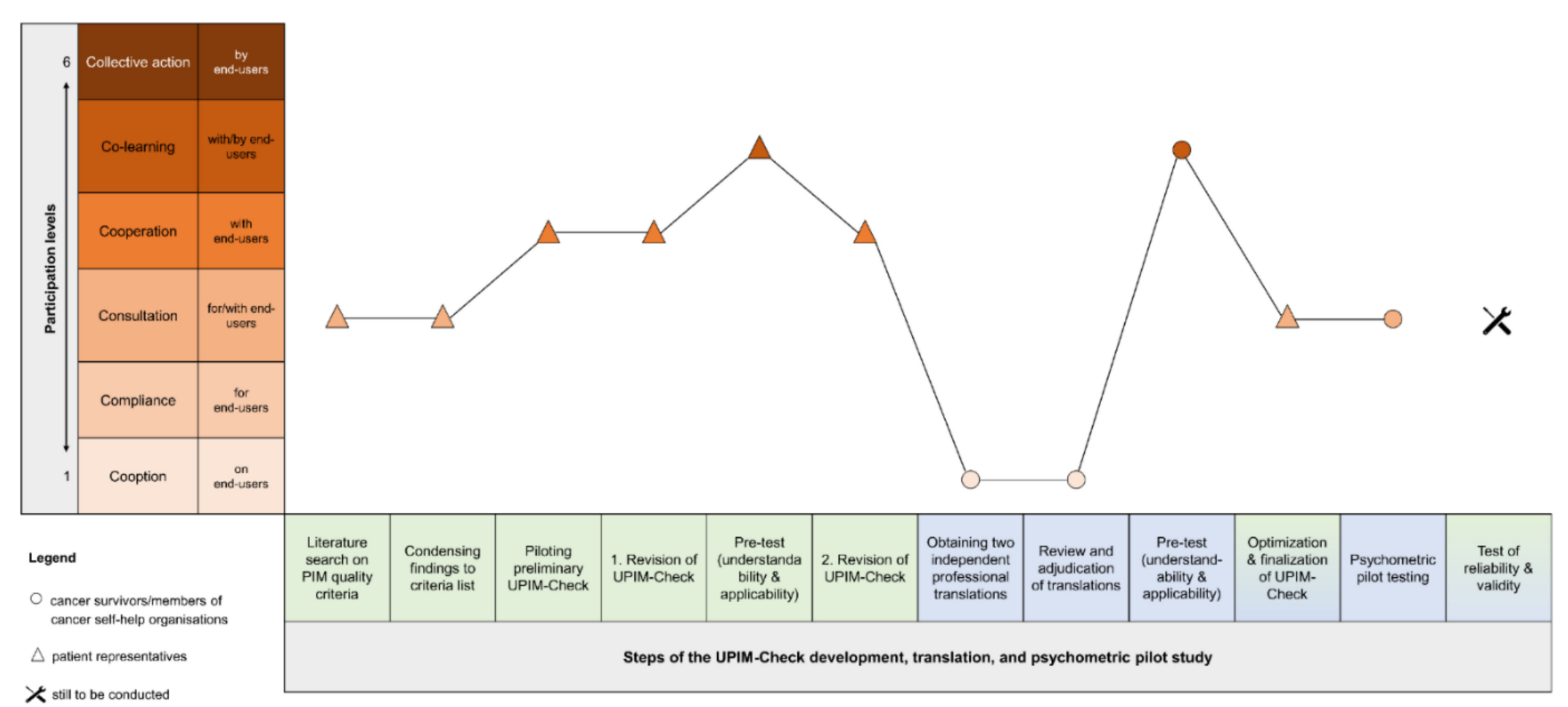

\section{X still to be conducted}

green $=$ UPIM-Check German version

blue $=$ UPIM-Check English version

Figure 4. Levels of end-users' participation (according to Cornwall (1996)) within the steps of the UPIM-Check development and translation process and psychometric pilot study. 
The values of the item-total correlations as measures of item discrimination were acceptable for 26 items (initial leaflet) and 17 items (optimized leaflet), respectively. Four items had a very low item -total correlation of $<0.20$ for both leaflets. These were: Q1.1 Up-to-date and technically correct; Q1.9 Further literature/points of contact; Q4.6 Coloured headings and highlighting of key points; Q4.8 Font colour. If these results are replicated in a representative validation study, items with no acceptable discrimination will have to be removed from the UPIM-Check, as they make no contribution to measure the construct [29].

Regarding construct validity (hypothesis 1), it was particularly restrictive that Q3: Structural readability was not significantly related to the overall rating. There might be a separate construct that should be addressed with comprehensibility tests [3]. The low acceptance of the empowering language criterion might be related to the average age of the pilot study participants ( $M=65.28$ years) and less familiarity with such formulations (e.g., post-war generation). The empowerment approach is relatively recent, especially in health care [38].

Hypotheses 2 (discrimination ability) and 3 (time-efficiency) were accepted. This showed that the UPIM-Check could distinguish between an initial and an optimized leaflet. Because of the open text fields, which were completed in the case of low scores, it is plausible that a worse overall score is associated with a longer completion time. Although data were collected by both scale and open text fields, the UPIM-Check proved to be very timeefficient and manageable.

\section{Strengths and Limitations}

The UPIM-Check was developed in an ongoing project (isPO). By pursuing the bottomup PHR approach, we avoided a research-to-practice gap [34] —in contrast to the top-down development of the initial isPO-PIM. Despite all the constraints (e.g., scarce resources, experts' scepticism), the participatory procedure was indispensable for optimizing the PIM to create a tailored fit for end-users (cancer patients) and usability in care. The process had to be conducted as quickly as possible to facilitate further programme implementation and enhance patients' programme acceptance with optimized PIM. Due to this highly practical setting and bottom-up approach on the one hand, and the rarity of similar development processes on the other hand, not every UPIM-Check development step was approached systematically, such as the selection of criteria/items based on a systematic review on PIM quality criteria.

With a sample size of $n=18$ and two assessed leaflets, the results of this study are not representative. They only give first indications on the psychometric properties of the UPIM-Check German version, so a comprehensive validation still has to be conducted. However, as the UPIM-Check's observation units are PIM and not people, especially the number of assessed PIMs has to be increased. For example, reliability testing for the DISCERN was conducted by only two raters assessing 31 PIM [17].

The UPIM-Check has been used only in the context of psycho-oncology so far, but its open format implies a high likelihood that it can be applied in a wide variety of care areas. This could generate larger PIM samples for future validation studies like for DISCERN [17] and PEMAT [13]. Also, the full potential of user groups in validating has not yet been realized.

Moreover, construct validity of the UPIM-Check was explored within the instrument, instead of testing the relationships with other PIM assessment instruments (convergent validity) $[29,30]$.

Besides participatory development (Figure 4), the mixed-methods response format consisting of a traffic light scale and open text fields is a unique feature of the UPIM-Check, e.g., in comparison to DISCERN and PEMAT. Knapp et al. [39] conducted PIM optimization based on quantitative user assessments and qualitative user interviews. They achieved a significantly higher understandability and acceptability of the improved PIM, whereas topdown PIM optimization using solely quantitative assessments resulted in minor differences in recruitment rates [40]. 
Unlike DISCERN and PEMAT, the items of the UPIM-Check do not cover a special area of PIM quality criteria. They consider content-related, structural and graphical requirements, whereas DISCERN focuses on reliability and completeness of information, and PEMAT on understandability and actionability. In contrast to UPIM-Check, DISCERN and PEMAT already have been validated $[13,17]$. Moreover, the items of DISCERN were notably formulated to assess PIM on treatment choices [2]. Such a specification was avoided in the UPIM-Check. Therefore, it can be applied for various PIMs, e.g., on diagnostics and care programmes.

Dissemination and accessibility of the UPIM-Check are guaranteed on the websites of all developers. The instrument is available for international use, as an English version was created following a recognized translation procedure [23,24].

\section{Conclusions}

The participation of the end-users was essential for the precise definition of the PIM quality criteria and the development of an end-user-friendly PIM quality instrument. The resulting UPIM-Check was rated as valid by experts and user-friendly by patients in both language versions. Through the quantitative and qualitative response format, the UPIM-Check enables both the assessment and optimization of PIM. Since both can be conducted with the same instrument, it is also very time-efficient. This was observed in the psychometric pilot study by the end-user group. However, patients often experience that they are hardly involved beyond the participation level of consultation $[9,41,42]$. With the PHR approach, end-users engaged in the UPIM-Check's development and psychometric pilot study (Figure 4), assisting the process with their specific knowledge.

With the UPIM-Check, a PIM quality instrument tool has become universally available, which appeared in a pilot study to be reliable and valid. It had already been used for optimizing and developing PIM [8,43], and it proved to be very end-user-friendly. It is aimed to support all groups involved in the development, optimization or evaluation of PIM, i.e., patients, relatives, patient representatives and professionals in health care, research and policy. The intuitive applicability enables end-users, in particular, to evaluate PIM according to scientific criteria. This empowers them to engage in PHR towards colearning and collective action [9]. In this way, end-users are strengthened in their role as co-researchers.

Author Contributions: Conceptualization, S.S., J.M. and T.K.; Formal analysis, S.S., J.M., C.H., N.C., S.H., A.A., A.G., K.S. and T.K.; Investigation, S.S., J.M., C.H., N.C., S.H., A.A., A.G., K.S. and T.K.; Methodology, S.S. and T.K.; Project administration, T.K.; Resources, C.H., S.H., A.A., A.G. and K.S.; Supervision, A.D.; Validation, S.S., C.H., N.C., A.D., H.P., N.S. and T.K.; Visualization, S.S.; Writingoriginal draft, S.S.; Writing—review and editing, J.M., C.H., N.C., A.D., S.H., A.A., A.G., K.S., H.P., N.S. and T.K. All authors have read and agreed to the published version of the manuscript.

Funding: This work did not receive any specific funding. However, the isPO project itself is funded by the Innovation Fund of the Federal Joint Committee, the G-BA (01NVF17022).

Institutional Review Board Statement: The study was performed according to the Declaration of Helsinki. The ethics committee of the Medical Faculty of the University of Cologne has approved the isPO project and its study design (No. 18-092; date of approval: 15 October 2018). The relevant national and European data protection regulations were considered for data collection. The isPO project study is registered in the German Clinical Trials Register (No. DRKS00015326).

Informed Consent Statement: All participants received oral and written information regarding the aim of the study and its voluntary nature and provided written consent to participate.

Data Availability Statement: The data presented in this study are available on reasonable request from the corresponding author. The data are not publicly available due to ethical and legal restrictions (participants of this study did not agree for their data to be shared publicly).

Acknowledgments: The authors thank the various cancer patient organizations from Germany, Great Britain, Ireland, USA, and Canada for their help in participant recruitment, and especially appreciate 
the members' participation engagement. Huge thanks to Susan Lee for being part of the English translation review team. We also thank Juliane Rackerseder for help with data collection.

Conflicts of Interest: The authors declare no conflict of interest. The funders had no role in the design of the study; in the collection, analyses, or interpretation of data; in the writing of the manuscript, or in the decision to publish the results.

\section{References}

1. Sänger, S.; Lang, B.; Klemperer, D.; Thomeczek, C.; Dierks, M.-L. Manual Patienteninformation: Empfehlungen zur Erstellung Evidenzbasierter Patienteninformationen; ÄZQ: Berlin, Germany, 2006; ISBN 978-3-9811002-0-4.

2. Moult, B.; Franck, L.S.; Brady, H. Ensuring quality information for patients: Development and preliminary validation of a new instrument to improve the quality of written health care information. Health Expect. 2004, 7, 165-175. [CrossRef]

3. Herm, K.; Linden, M. Qualitätssicherung von schriftlichen Patienteninformationen. Psychother. Psychosom. Med. Psychol. 2013, 63, 176-184. [CrossRef] [PubMed]

4. Zhang, Y.; Sun, Y.; Xie, B. Quality of health information for consumers on the web: A systematic review of indicators, criteria, tools, and evaluation results. J. Assn. Inf. Sci. Technol. 2015, 66, 2071-2084. [CrossRef]

5. Jenniches, I.; Lemmen, C.; Cwik, J.C.; Kusch, M.; Labouvie, H.; Scholten, N.; Gerlach, A.; Stock, S.; Samel, C.; Hagemeier, A.; et al. Evaluation of a complex integrated, cross-sectoral psycho-oncological care program (isPO): A mixed-methods study protocol. BMJ Open 2020, 10, e034141. [CrossRef] [PubMed]

6. Kusch, M.; Labouvie, H.; Schiewer, V.; Talalaev, N.; Cwik, J.C.; Bussmann, S.; Vaganian, L.; Gerlach, A.; Dresen, A.; Cecon, N.; et al. Integrated, cross-sectoral psycho-oncology (isPO): A new form of care for newly diagnosed cancer patients in Germany. BMC Health Services Res. 2020. Manuscript submitted for publication.

7. Salm, S.; Cecon, N.; Jenniches, I.; Pfaff, H.; Scholten, N.; Dresen, A.; Krieger, T. Conducting a prospective evaluation of the development of a complex psycho-oncological care programme (isPO) in Germany. Eval. Program Plan. 2020. Manuscript submitted for publication.

8. Krieger, T.; Salm, S.; Dresen, A.; Arning, A.; Schwickerath, K.; Göttel, A.; Houwaart, S.; Pfaff, H.; Cecon, N. Patient's perspective matters: Optimization of Patient Information Material for the integrated, cross-sectoral psycho-oncology (isPO) project using Participatory Health Research. Health Expect. 2021. Manuscript submitted for publication.

9. Cornwall, A. Towards participatory practice: Participatory rural appraisal (PRA) and the participatory process. In Participatory Research in Health: Issues and Experiences; Zed Books: London, UK, 1996; pp. 94-107.

10. Doak, C.C.; Doak, L.G.; Root, J.H. Assessing Suitability of Materials: Teaching Patients with Low Literacy Skills; JB Lippincott: Philadelphia, PA, USA, 1996.

11. Charnock, D.; Shepperd, S.; Needham, G.; Gann, R. DISCERN: An instrument for judging the quality of written consumer health information on treatment choices. J. Epidemiol. Community Health 1999, 53, 105-111. [CrossRef] [PubMed]

12. Clayton, L.H. TEMPtEd: Development and psychometric properties of a tool to evaluate material used in patient education. J. Adv. Nurs. 2009, 65, 2229-2238. [CrossRef]

13. Shoemaker, S.J.; Wolf, M.S.; Brach, C. Development of the Patient Education Materials Assessment Tool (PEMAT): A new measure of understandability and actionability for print and audiovisual patient information. Patient Educ. Couns. 2014, 96, 395-403. [CrossRef] [PubMed]

14. Loeb, S.; Sengupta, S.; Butaney, M.; Macaluso, J.N.; Czarniecki, S.W.; Robbins, R.; Braithwaite, R.S.; Gao, L.; Byrne, N.; Walter, D.; et al. Dissemination of Misinformative and Biased Information about Prostate Cancer on YouTube. Eur. Urol. 2019, 75, 564-567. [CrossRef]

15. Nghiem, A.Z.; Mahmoud, Y.; Som, R. Evaluating the quality of internet information for breast cancer. Breast 2016, 25, 34-37. [CrossRef]

16. Nicholls, S.; Hankins, M.; Hooley, C.; Smith, H. A survey of the quality and accuracy of information leaflets about skin cancer and sun-protective behaviour available from UK general practices and community pharmacies. J. Eur. Acad. Dermatol. Venereol. 2009, 23, 566-569. [CrossRef]

17. Rees, C.E.; Ford, J.E.; Sheard, C.E. Evaluating the reliability of DISCERN: A tool for assessing the quality of written patient information on treatment choices. Patient Educ. Couns. 2002, 47, 273-275. [CrossRef]

18. Ryan, L.; Logsdon, M.C.; McGill, S.; Stikes, R.; Senior, B.; Helinger, B.; Small, B.; Davis, D.W. Evaluation of printed health education materials for use by low-education families. J. Nurs. Scholarsh. 2014, 46, 218-228. [CrossRef]

19. Smith, F.; Carlsson, E.; Kokkinakis, D.; Forsberg, M.; Kodeda, K.; Sawatzky, R.; Friberg, F.; Öhlén, J. Readability, suitability and comprehensibility in patient education materials for Swedish patients with colorectal cancer undergoing elective surgery: A mixed method design. Patient Educ. Couns. 2014, 94, 202-209. [CrossRef] [PubMed]

20. Weintraub, D.; Maliski, S.L.; Fink, A.; Choe, S.; Litwin, M.S. Suitability of prostate cancer education materials: Applying a standardized assessment tool to currently available materials. Patient Educ. Couns. 2004, 55, 275-280. [CrossRef]

21. Brütting, J.; Reinhardt, L.; Bergmann, M.; Schadendorf, D.; Weber, C.; Tilgen, W.; Berking, C.; Meier, F. Quality, Readability, and Understandability of German Booklets Addressing Melanoma Patients. J. Cancer Educ. 2019, 34, 760-767. [CrossRef]

22. Janssen, S.; Fahlbusch, F.B.; Käsmann, L.; Rades, D.; Vordermark, D. Radiotherapy for prostate cancer: DISCERN quality assessment of patient-oriented websites in 2018. BMC Urol. 2019, 19, 42. [CrossRef] [PubMed] 
23. European Social Survey. ESS Round 9Translation Guidelines. Available online: https://www.europeansocialsurvey.org/docs/ round9/methods/ESS9_translation_guidelines.pdf (accessed on 17 December 2020).

24. Harkness, J.A. Questionnaire Translation. In Cross-Cultural Survey Methods; Harkness, J.A., van de Vijver, F.J.R., Mohler, P.P., Eds.; Wiley: Hoboken, NJ, USA, 2003; pp. 35-56. ISBN 978-0-471-38526-4.

25. Körner, M.; Fröhlich, M.; Wirtz, M.; Göritz, A.S. Psychometrische Überprüfung eines Klinikkultur-Fragebogens (KKF-15). Zeitschrift für Arbeits- und Organisationspsychologie AEO 2015, 59, 30-45. [CrossRef]

26. Findley, W.G. A rationale for evaluation of item discrimination statistics. Educ. Psychol. Meas. 1956, 16, 175-180. [CrossRef]

27. Howard, K.I.; Forehand, G.A. A Method for Correcting Item-Total Correlations for the Effect of Relevant Item Inclusion. Educ. Psychol. Meas. 1962, 22, 731-735. [CrossRef]

28. Kline, P. A Handbook of Test Construction: Introduction to Psychometric Design; Routledge: London, UK, 2015; ISBN 9781317444596.

29. Streiner, D.L.; Norman, G.R.; Cairney, J. Health Measurement Scales: A Practical Guide to their Development and use, 5th ed.; Oxford University Press: Oxford, UK, 2015; ISBN 9780199685219.

30. Fayers, P.M.; Machin, D. Quality of Life: The Assessment, Analysis, and Reporting of Patient-Reported Outcomes, 3rd ed.; John Wiley \& Sons Inc.: Chichester, West Sussex, UK; Hoboken, NJ, USA, 2016; ISBN 1444337955.

31. Cronbach, L.J. Coefficient alpha and the internal structure of tests. Psychometrika 1951, 16, 297-334. [CrossRef]

32. Taylor, R. Interpretation of the Correlation Coefficient: A Basic Review. J. Diagn. Med. Sonogr. 1990, 6, 35-39. [CrossRef]

33. Krieger, T.; Specht, R.; Errens, B.; Hagen, U.; Dorant, E. Caring for Family Caregivers of Geriatric Patients: Results of a Participatory Health Research Project on Actual State and Needs of Hospital-Based Care Professionals. Int. J. Environ. Res. Public Health 2020, 17, 5901. [CrossRef]

34. Cargo, M.; Mercer, S.L. The value and challenges of participatory research: Strengthening its practice. Annu. Rev. Public Health 2008, 29, 325-350. [CrossRef]

35. Richardson, S.J.; Carroll, C.B.; Close, J.; Gordon, A.L.; O’Brien, J.; Quinn, T.J.; Rochester, L.; Sayer, A.A.; Shenkin, S.D.; van der Velde, N.; et al. Research with older people in a world with COVID-19: Identification of current and future priorities, challenges and opportunities. Age Ageing 2020, 49, 901-906. [CrossRef]

36. Flores, S.; Kurian, N.; Yohannan, A.; Persaud, C.; Saif, M.W. Consequences of the COVID-19 Pandemic on Cancer Clinical Trials. Cancer Med. J. 2021, 4, 38-43.

37. Tavakol, M.; Dennick, R. Making sense of Cronbach's alpha. Int. J. Med. Educ. 2011, 2, 53-55. [CrossRef] [PubMed]

38. Feste, C.; Anderson, R.M. Empowerment: From philosophy to practice. Patient Educ. Couns. 1995, 26, 139-144. [CrossRef]

39. Knapp, P.; Raynor, D.K.; Silcock, J.; Parkinson, B. Can user testing of a clinical trial patient information sheet make it fit-forpurpose? A randomized controlled trial. BMC Med. 2011, 9, 89. [CrossRef] [PubMed]

40. Parker, A.; Knapp, P.; Treweek, S.; Madhurasinghe, V.; Littleford, R.; Gallant, S.; Sullivan, F.; Schembri, S.; Rick, J.; Graffy, J.; et al. The effect of optimised patient information materials on recruitment in a lung cancer screening trial: An embedded randomised recruitment trial. Trials 2018, 19, 503. [CrossRef] [PubMed]

41. Domecq, J.P.; Prutsky, G.; Elraiyah, T.; Wang, Z.; Nabhan, M.; Shippee, N.; Brito, J.P.; Boehmer, K.; Hasan, R.; Firwana, B.; et al. Patient engagement in research: A systematic review. BMC Health Serv. Res. 2014, 14, 89. [CrossRef] [PubMed]

42. Harrison, J.D.; Auerbach, A.D.; Anderson, W.; Fagan, M.; Carnie, M.; Hanson, C.; Banta, J.; Symczak, G.; Robinson, E.; Schnipper, J.; et al. Patient stakeholder engagement in research: A narrative review to describe foundational principles and best practice activities. Health Expect. 2019, 22, 307-316. [CrossRef] [PubMed]

43. Rackerseder, J.; Hornbach, C.; Dicks, P.; Kerek-Bodden, H.; Arning, A.; Schwickerath, K.; Göttel, A.; Krieger, T. Designing a patient-friendly website for newly-diagnosed cancer patients with the Participatory Health Research approach. 2021; Manuscript in preparation. 